\title{
UTILIZAÇÃO DE ESGOTOS DOMÉSTICOS TRATADOS ATRAVÉS DE UM SISTEMA BIOLÓGICO NA PRODUÇÃO DE MUDAS DE Croton floribundus Spreng. (CAPIXINGUI) E Copaifera langsdorffii Desf. (COPAÍBA) ${ }^{1}$
}

\author{
Danielle Camargo Celentano Augusto 2 , Iraê Amaral Guerrini ${ }^{3}$, Vera Lex Engel ${ }^{4}$ e Guillaume Xavier Rousseau ${ }^{5}$
}

\begin{abstract}
RESUMO - O presente trabalho teve por objetivo o aproveitamento da água residuária proveniente de um sistema biológico de tratamento de esgotos domésticos como alternativa à fertirrigação convencional de viveiros florestais, visando a produção de mudas de Croton floribundus (capixingui) e Copaifera langsdorffii (Copaíba) via subirrigação. As variáveis avaliadas mensalmente foram altura e diâmetro do coleto da muda e, ao final do experimento, peso da matéria seca da parte aérea e da raiz, área foliar, razão parte aérea/ raiz, análise nutricional foliar, análises químicas do substrato antes e após o ensaio e análises nutricionais periódicas da água residuária. $\mathrm{O}$ crescimento das plantas, em geral, foi superior no tratamento convencional com adubos minerais. O desenvolvimento do sistema radicular foi favorecido no tratamento com água residuária, o que pode ser característica desejável para maior sobrevivência das mudas no campo. Os resultados mostraram que a água residuária pode ser utilizada na fertirrigação de viveiros para produção das espécies estudadas, pois todas as plantas se mostraram vigorosas, com bom desenvolvimento, sem mortalidade, deficiência ou toxidez. Entretanto, constatou-se que essas mudas necessitarão de um maior tempo no viveiro, quando comparadas com as produzidas com fertilizantes minerais.
\end{abstract}

Palavras-chave: Fertirrigação, água residuária, produção de mudas, Croton floribundus e Copaifera langsdorffii.

\section{USE OF DOMESTIC WASTEWATER AFTER BIOLOGICAL TREATMENT SYSTEM FOR Croton floribundus Spreng. AND Copaifera langsdorffii Desf. SEEDLING PRODUCTION}

\begin{abstract}
This work aimed to study the use of treated domestic wastewater from a biological treatment system as an alternative for a seedling-nursery conventional fertirrigation (irrigation fertilization) of Croton floribundus Spreng. (Euphorbiaceae) and Copaifera langsdorffii Desf. (Leguminosae Caesalpinioideae) production. The variables analyzed monthly were seedling height and diameter and shoot and root dry matter weight, leaf area, shoot/root ratio, leaf and substrate chemical status (before and after the experiment) and periodical waste water nutritional analyses. Plant growth was greater when chemical fertilizers were used, but root development was greater when treated wastewater was used (which was thought to promote increased survival in the field). The results showed that wastewater can be used for fertirrigation of tree nurseries, since all plants have demonstrated vigor and good development with no mortality, deficiency or toxicity symptoms. Seedlings fertirrigated with wastewater, however, will spend more nursery time, when compared to those fertirrigated with mineral fertilizers.
\end{abstract}

Key words: $\quad$ Fertirrigation, wastewater, tree seedling production, Croton floribundus and Copaifera langsdorfii.

1 Recebido para publicação em 1.8.2002.

Aceito para publicação em 12.5.2003.

2 Dep. de Recursos Naturais da Faculdade de Ciências Agráficas da Universidade Estadual de São Paulo - FCA-UNESP, fazenda Lageado s/n, Caixa Postal 237, Botucatu/SP. <danicelentano@fca.unesp.br> Bolsista da FAPESP; ${ }^{3}$ Dep. de Recursos Naturais da FCA-UNESP, <iguerrini@fca.unesp.br>, Bolsista do CNPq; ${ }^{4}$ Dep. de Recursos Naturais da FCA-UNESP, <veralex@fca.unesp.br>. ${ }^{5}$ Department de Phytologie, Faculté des Sciences de l'Agriculture et de l'Alimentation, Université LAVAL, Sainte Foy, G1K 7P4, Québec, Canada, <guilirous@yahoo.ca>. 


\section{INTRODUÇÃO}

A água é o mais precioso bem do planeta Terra, sendo o maior constituinte e o principal responsável pela vida. Em função disto, nesses últimos anos vem se tornando uma das maiores preocupações mundiais, levandose a acreditar em uma iminente crise mundial de abastecimento (Postel et al., 1996).

Gasi (1988) afirmou que as opções para a recuperação ou o tratamento das águas residuárias de origem doméstica, industrial ou agrícola envolvem diferentes alternativas, muitas delas complexas e caras, e outras de baixo custo e estruturas simples. Um exemplo de uma alternativa simples e de baixo custo é aquela empregada a fazenda Experimental Lageado da UNESP, em Botucatu-SP, que possui um sistema de coleta e tratamento do esgoto através de plantas aquáticas, para uma comunidade rural de 15 casas e 65 habitantes (Comunidade Olaria). O emprego de diferentes plantas aquáticas produziu resultados satisfatórios na remoção de carga poluidora presente no efluente gerado por esta comunidade rural (Guimarães et al., 2000).

Pensando na reutilização futura de efluentes, a atividade florestal, por suas peculiaridades, apresentase como uma alternativa promissora, principalmente por não envolver produção de alimentos para consumo humano e nem riscos à saúde (Cromer, 1980). Além disto, por ser realizada em larga escala tem a potencialidade de consumir um grande volume de efluentes. $\mathrm{O}$ lodo de esgoto ou biossólido, embora ainda não tenha sido amplamente testado no Brasil, já apresenta alguns resultados promissores, seja na fase de produção de mudas de espécies florestais (Morais et al., 1997) ou de implantação de reflorestamento (Gonçalves et al., 2000a; Poggiani et al., 2000). Esses estudos já estão avançados em outros países, inclusive com aplicações comerciais em empresas florestais (Cole et al., 1986; Harrison et al., 1993; Henry et al., 1994).

Entretanto, a parte sólida do esgoto (lodo) corresponde a apenas $0,1 \%$ da sua composição, sendo $99,9 \%$ composta pelas águas residuárias (Fernandes, 2000). Estudos realizados em outros países têm demonstrado a eficiência do uso das águas residuárias na fertirrigação de culturas agrícolas com a obtenção de excelentes resultados, uma vez que são ricas em nutrientes (Bastos, 1999).

O objetivo deste trabalho foi estudar uma nova forma de aproveitamento de resíduos na atividade florestal, estudando o efeito do efluente líquido produzido no processo de tratamento de esgoto como alternativa para a fertirrigação na produção de mudas de espécies florestais.

\section{MATERIAL E MÉTODOS}

Este experimento foi realizado em casa de vegetação, no Viveiro Florestal do Departamento de Recursos Naturais da Faculdade de Ciências Agronômicas (FCA-UNESP) em Botucatu-SP, utilizando os efluentes líquidos resultantes do tratamento biológico de esgoto da Comunidade Olaria, da Fazenda Experimental Lageado da FCA.

\subsection{Espécies Estudadas}

As espécies utilizadas no ensaio foram Croton floribundus Spreng. (capixingui), pioneira da família Euphorbiaceae, utilizada em reflorestamentos mistos em áreas degradadas; e Copaifera langsdorffii Desf. (copaíba), leguminosa da família Leguminosae Caesalpinioideae, que possui madeira de ótima qualidade e fornece o óleo-de-copaíba, utilizado para fins medicinais.

\subsection{Produção das Mudas}

Foram utilizados tubetes de polietileno de $120 \mathrm{ml}$ de capacidade, com substrato constituído de $60 \%$ de casca de Pinus decomposta, $15 \%$ de vermiculita (granulometria fina), $25 \%$ de húmus e terra vegetal, cujas análises químicas foram realizadas de acordo com a metodologia do LABORATÓRIO NACIONAL DE REFERÊNCIA VEGETAL (1988).

\subsection{Fertirrigação}

A fertirrigação, utilizando tanto água residuária como água limpa mais fertilizantes minerais (tratamento convencional), foi realizada via subirrigação, sistema em que os tubetes, dentro de uma bandeja galvanizada, permaneceram continuamente submersos até $2 \mathrm{~cm}$ da sua base, absorvendo água por capilaridade. O sistema foi controlado por uma bóia, o que proporcionou distribuição uniforme dos nutrientes para todas as plantas.

A água residuária utilizada foi proveniente da Estação Biológica de Tratamento de Esgotos da Comunidade Rural Olaria, que é composta por 15 casas e aproximadamente 65 habitantes. Nesta estação de tratamento biológico o esgoto doméstico passa por 
diferentes caixas de fibrocimento. Nas três primeiras caixas há decantação, separando o material sólido mais grosseiro; na quarta, o material vai para caixas com brita e terra, onde há uma filtragem melhor. Em seguida, o resíduo líquido passa por um leito filtrante composto por três partes de casca de arroz e uma parte de solo textura média, além de diferentes espécies aquáticas (junco, aguapé e taboa), que retiram mais matéria orgânica da água. Ao final do tratamento a água continua não sendo própria ao consumo humano, pois ainda apresenta matéria orgânica e vestígios de coliformes fecais.

A água utilizada no experimento foi aquela coletada nas saídas das caixas com plantas, última fase do tratamento. As análises químicas $(\mathrm{pH}$, macro e micronutrientes) e de condutividade elétrica da água residuária foram feitas de acordo com uma adaptação de Malavolta et al. (1997) e EMPRESA BRASILEIRA DE PESQUISA AGROPECUÁRIA - EMBRAPA (1997) e realizadas pelo Laboratório de Análises de Plantas e Solos do Departamento de Recursos Naturais - FCA/UNESP; essas análises foram realizadas periodicamente durante o experimento e estão apresentadas nos resultados.

A adubação na fertirrigação convencional foi realizada com nitrato de amônio, nitrato de potássio e monoamônio fosfato (MAP), de acordo com a adubaçãopadrão do viveiro florestal da FCA. Em função desta adubação-padrão, foram calculadas as doses de nutrientes adicionadas por tubete, e, a partir desses dados, obtevese o que foi fornecido semanalmente para as plantas neste tratamento: $6 \mathrm{~g}$ de nitrato de potássio, $1 \mathrm{~g}$ de MAP e 2,5 g de nitrato de amônio.

\subsection{Delineamento Experimental}

Foi estudado o desenvolvimento de duas espécies sob dois diferentes tratamentos, fertirrigação convencional e com água residuária, tendo cada tratamento quatro parcelas com 25 plantas cada, sendo consideradas úteis as nove plantas centrais. Os tratamentos foram comparados através do teste $t$ para amostras independentes, entre tratamentos para uma mesma espécie. Em algumas variáveis estudadas (altura, área foliar e peso seco da parte aérea do Croton floribundus), através do teste de Bartlett para homogeneidade de variância, constatou-se que as variâncias não eram homocedásticas (valores discrepantes), havendo, portanto, necessidade de analisar esses dados através do teste U de MonnWhitney (não-paramétrico).

\subsection{Coleta e Análise dos Dados}

Os parâmetros altura e diâmetro de coleto das mudas foram avaliados mensalmente, até cinco meses para o capixingui e sete meses para a copaíba, com o uso de régua graduada e paquímetro digital, respectivamente. A área foliar foi medida ao final do experimento para cada espécie, utilizando-se o aparelho AAM-8 Hayoshi Denkoh, bem como a produção de massa seca da parte aérea e das raízes das plantas úteis de cada parcela, sendo consideradas, nesta avaliação, apenas as raízes dentro do tubete. $\mathrm{O}$ sistema de subirrigação causou um grande crescimento do sistema radicular do capixingui, tendo sido necessária a realização de podas periódicas das raízes.

Foram feitas análises químicas de macro e micronutrientes nos tecidos foliares das mudas a fim de avaliar o seu estado nutricional ao final do experimento, de acordo com a metodologia de Malavolta et al. (1997). A metodologia é baseada na digestão nitroperclórica para $\mathrm{P}, \mathrm{K}$, $\mathrm{Mg}, \mathrm{S}, \mathrm{Cu}, \mathrm{Fe}, \mathrm{Mn}$ e $\mathrm{Zn}$, digestão via seca para o B e sulfúrica para $\mathrm{o} \mathrm{N}$ e determinação micro-Kjeldahl para $\mathrm{N}$, por colorimetria para $\mathrm{P}$, turbidimetria para $\mathrm{S}$, azometria-H para B e espectrofotometria de absorção atômica para os demais elementos. A partir dos resultados desta análise foi calculado o acúmulo de nutrientes nas folhas das diferentes espécies.

\section{RESULTADOS E DISCUSSÃO}

\subsection{Análise Química das Águas}

O teor de macronutrientes na água do tratamento convencional é bastante superior ao da água residuária. Entretanto, para ambos os tratamentos e espécies, a taxa de sobrevivência das mudas foi de $100 \%$ e a incidência de pragas e doenças foi de $0 \%$, mostrando que embora o teor de nutrientes tenha sido baixo no tratamento com água residuária ele foi suficiente para o desenvolvimento de mudas sadias e vigorosas.

\subsection{Análise Química do Substrato}

Por meio das análises dos substratos dos diferentes tratamentos ao final do experimento (Quadro 2), constatase que eles registraram quantidades semelhantes de nutrientes. Comparadas à análise inicial do substrato, observa-se que ao fim do experimento houve redução nos teores de matéria orgânica, $\mathrm{C}$ total, relação $\mathrm{C} / \mathrm{N}$ e

R. Árvore, Viçosa-MG, v.27, n.3, p.335-342, 2003 
Quadro 1 - Análise química e de condutividade elétrica (CE) da água residuária e da fertirrigação convencional

Table 1 -Chemical analyses and electrical conductivity (CE) of the wastewater and conventional fertigation

\begin{tabular}{|c|c|c|c|c|c|c|c|c|c|c|c|c|c|}
\hline \multirow{2}{*}{ Tratamento } & $\mathrm{N}$ & $\mathrm{P}$ & $\mathrm{K}$ & $\mathrm{Ca}$ & $\mathrm{Mg}$ & $\mathrm{S}$ & $\mathrm{Na}$ & $\mathrm{Cu}$ & $\mathrm{Fe}$ & $\mathrm{Mn}$ & $\mathrm{Zn}$ & $\mathrm{pH}$ & \multirow{2}{*}{$\frac{\text { C.E. }}{(\mathrm{dS} / \mathrm{m})}$} \\
\hline & \multicolumn{10}{|c|}{$(\mathrm{mg} / \mathrm{l})$} & \multicolumn{2}{|c|}{$\left(\mathrm{CaCl}_{2}\right)$} & \\
\hline A.Residuária ${ }^{\underline{1}}$ & 161,7 & 6,2 & 23,2 & 29,1 & 4,8 & 6,3 & 48,1 & 0,01 & 2,60 & 0,10 & 0,10 & 7,1 & 0,7 \\
\hline Convencional ${ }^{2 /}$ & 229 & 15,1 & 119,3 & - & - & - & - & - & - & - & - & 7,0 & 1,9 \\
\hline
\end{tabular}

${ }^{1 /}$ Média de nove amostragens ao longo do experimento $\mathrm{e}^{\underline{2} /}$ média de sete amostragens ao longo do experimento.

quase todos os elementos, com exceção do N, K, Zn e $\mathrm{Na}$, ocorrendo pequena variação nos valores de $\mathrm{pH}$. Constatou-se aumento no teor de $\mathrm{Na}$ em ambos os tratamentos, mas com superioridade no tratamento com água residuária, mostrando, assim, que houve acúmulo de sais em ambos os tratamentos. Em função do uso e da decomposição do material, houve redução no teor de $\mathrm{Ce}$ aumento no teor de $\mathrm{N}$, o que provou diminuição na relação $\mathrm{C} / \mathrm{N}$ em comparação ao substrato original, causada pela ação do tempo na mineralização da matéria orgânica. Comparando os teores de matéria orgânica em ambos os tratamentos, pode-se observar a tendência de o tratamento convencional apresentar maiores valores. Embora tal fato não tenha sido testado estatisticamente, acredita-se que a maior atividade microbiológica no tratamento com água residuária tenha acelerado a decomposição da matéria orgânica.

\subsection{Medição da Altura Total, da Área Foliar e do Diâmetro de Coleto}

O desenvolvimento em altura e diâmetro do capixingui e sua área foliar foram significativamente superiores no tratamento convencional (Quadro 3), fato ocorrido provavelmente pela maior concentração de macronutrientes na solução nutritiva em relação à água residuária. O capixingui é uma espécie pioneira que, segundo Gonçalves et al. (2000 b), apresenta alta taxa de crescimento, alta demanda de nutrientes, alta capacidade de absorção e alta taxa de acúmulo de nutrientes em tecidos vegetais. Segundo dados destes autores, o crescimento em altura dessa espécie, em um sistema convencional de produção de mudas (microaspersão), chegou a $32 \mathrm{~cm}$ em 130 dias de experimento, valor inferior ao do tratamento convencional ao final deste ensaio (150 dias), mas superior ao obtido com água residuária, o que pode ser um fator positivo da subirrigação de mudas florestais quando comparada a sistemas de irrigação convencionais.
A copaíba é uma espécie-clímax que, segundo Gonçalves et al. (2000b), apresenta crescimento lento, o que significa que suas exigências nutricionais são baixas comparadas com as do capixingui, bem como sua capacidade de absorção de nutrientes e resposta à fertilização. Quanto à altura das plantas, as diferenças estatísticas entre os tratamentos para esta espécie se deram a partir do quinto mês do ensaio, diferentemente do capixingui, que apresentou diferenças a partir do segundo mês. Já o

Quadro 2 - Análise química do substrato antes do início e ao final do experimento

Table 2 - Chemical analyses of the substrate before and after the experiment

\begin{tabular}{|l|r|r|r|}
\hline \multirow{2}{*}{ Variável } & \multicolumn{3}{|c|}{ Resultado de Base Seca $\left(110^{\circ} \mathrm{C}\right)$} \\
\cline { 2 - 4 } & \multirow{3}{*}{ Início } & \multicolumn{2}{|c|}{ Final } \\
\cline { 2 - 4 } & & $\mathrm{g} / \mathrm{kg})$ \\
\hline & 7,10 & 8,40 & 10,00 \\
\hline $\mathrm{N}$ total & 5,40 & 4,70 & 3,20 \\
$\mathrm{P}_{2} \mathrm{O}$ total & 1,20 & 1,40 & 1,70 \\
$\mathrm{~K}_{2} \mathrm{O}$ total & 630,00 & 270,00 & 310,00 \\
Matéria Orgânica & 250,00 & 150,00 & 172,20 \\
Carbono total & 9,40 & 8,10 & 5,80 \\
Ca total & 6,50 & 1,20 & 1,10 \\
$\mathrm{Mg}$ total & 1,10 & 0,50 & 0,00 \\
$\mathrm{~S}$ total & \multicolumn{3}{|c|}{$(\mathrm{mg} / \mathrm{l})$} \\
\hline & 114,00 & 138,00 & 156,00 \\
\hline $\mathrm{Zn}$ total & 236,00 & 176,00 & 104,00 \\
$\mathrm{Mn}$ total & 38,00 & 36,00 & 30,00 \\
Cu total & 120,00 & $4.200,00$ & $3.100,00$ \\
$\mathrm{Na}$ total & $2.950,00$ & 720,00 & 800,00 \\
Ferro total & \multicolumn{3}{|c|}{} \\
\hline & 5,4 & 5,1 & 5,4 \\
\hline $\mathrm{pH}\left(\mathrm{CaCl}{ }_{2} 0,01 \mathrm{M}\right)$ & $35 / 1$ & $18 / 1$ & $17 / 1$ \\
Relação C/N & \multicolumn{3}{|c|}{ Convencional } \\
\hline
\end{tabular}


diâmetro das plantas não apresentou diferenças estatísticas entre os tratamentos, embora seja possível notar a tendência de o tratamento com água residuária proporcionar um maior diâmetro, ao contrário do que ocorreu para o capixingui.

\subsection{Peso da Matéria Seca}

Os dados de produção de matéria seca do capixingui (Quadro 4) foram significativamente superiores para as plantas do tratamento convencional, tanto para a parte aérea quanto para a raiz, possivelmente em função da maior concentração de macronutrientes disponíveis nesse tratamento, uma vez que essa espécie apresenta alta taxa de acúmulo de nutrientes.

Já para a copaíba, embora a área foliar das plantas do tratamento convencional tenha sido significativamente maior que as do tratamento com água residuária, a matéria seca da parte aérea e das raízes não apresentaram diferenças significativas. Quanto à razão raiz/ parte aérea, constatou-se que o tratamento com água residuária favoreceu ambas as espécies, pois permitiu melhor desenvolvimento radicular em relação à parte aérea. Tal fato indica que, embora o desenvolvimento tenha sido inferior (mais lento) no tratamento com água residuária, as plantas apresentaram maior equilíbrio entre a parte

Quadro 3 - Médias e desvios-padrão de altura, diâmetro do coleto e área foliar para as mudas de Croton floribundus (cinco meses) e Copaifera langsdorffii (sete meses)

Table 3 - Height, diameter and leaf area averages and standard deviations for Croton floribundus (5 months) and Copaifera langsdorffii (7 months) seedlings

\begin{tabular}{|c|c|c|c|c|c|c|c|}
\hline & \multirow[b]{2}{*}{ Tratamento } & \multicolumn{6}{|c|}{ Variável } \\
\hline & & $\begin{array}{l}\text { Altura } \\
(\mathrm{cm})\end{array}$ & & $\begin{array}{l}\text { Diâmetro } \\
\text { (mm) }\end{array}$ & & $\begin{array}{c}\text { Área foliar } \\
\left(\mathrm{cm}^{2}\right)\end{array}$ & \\
\hline $\bar{b}_{0}$ & Á. Residuária & $20,01+/-3,44$ & $(\mathrm{u}=2,000)$ & $3,60+/-0,49$ & $(\mathrm{t}=8,897)$ & $135,21+/-30,7$ & $(\mathrm{u}=2,000)$ \\
\hline త్రీ & Convencional & $43,59+/-8,70$ & $(\mathrm{p}<0,0001)$ & $4,69+/-0,55$ & $(\mathrm{p}<0,0001)$ & $290,97+/-58,9$ & $(\mathrm{p}<0,0001)$ \\
\hline శี & Á. Residuária & $11,63+/-2,58$ & $(\mathrm{t}=4,378)$ & $3,87+/-0,40$ & (n.s.) & $78,47+/-32,3$ & $(\mathrm{t}=2,391)$ \\
\hline ن & Convencional & $14,54+/-3,05$ & $(\mathrm{p}<0,0001)$ & $3,71+/-0,47$ & & $110,70+/-43,2$ & $(p=0,0233)$ \\
\hline
\end{tabular}

Quadro 4 - Peso da matéria seca da parte aérea, da raiz e razão raiz/ parte aérea (médias e desvios-padrão) para capixingui (cinco meses) e copaíba (sete meses)

Table 4 - Shoot and root dry weight and shoot/root ratios (averages and standard deviations) for Croton floribundus (5 months) and Copaifera langsdorffii (7 months) seedlings

\begin{tabular}{|c|c|c|c|c|c|c|c|}
\hline & \multirow{3}{*}{$\begin{array}{l}\text { Tratamento } \\
\text { Á. Residuária }\end{array}$} & \multicolumn{4}{|c|}{ Matéria Seca (g/muda) } & \multirow{2}{*}{\multicolumn{2}{|c|}{ Razão Raiz/Parte Aérea }} \\
\hline & & Parte aérea & & Raiz & & & \\
\hline \multirow{2}{*}{ 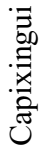 } & & $1,64+/-0,36$ & $(\mathrm{t}=2,000)$ & $1,25+/-0,25$ & $(t=3,404)$ & $0,77+/-0,08$ & $(\mathrm{t}=11,742)$ \\
\hline & Convencional & $3,79+/-0,94$ & $(\mathrm{u}<0,0001)$ & $1,64+/-0,40$ & $(\mathrm{p}=0,0019)$ & $0,44+/-0,07$ & $(\mathrm{p}<0,0001)$ \\
\hline \multirow{2}{*}{ 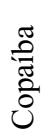 } & Á. Residuária & $0,83+/-0,29$ & (n.s.) & $0,90+/-0,29$ & (n.s.) & $1,18+/-0,43$ & $(\mathrm{t}=4,008)$ \\
\hline & Convencional & $0,99+/-0,40$ & & $0,69+/-0,34$ & & $0,70+/-0,20$ & $(p=0,0004)$ \\
\hline
\end{tabular}


aérea e a raiz, o que pode proporcionar melhor sobrevivência no campo, não apenas em função do melhor equilíbrio físico (responsável pela sustentação da muda), mas também pela maior capacidade de absorção de água e melhor balanço entre a transpiração e a absorção.

\subsection{Avaliação do Estado Nutricional das Plantas}

O capixingui apresentou valores significativamente maiores nas plantas do tratamento convencional somente para os teores de K e Mn (Quadro 5). O maior teor de K nas plantas do tratamento convencional já era esperado, em função da adubação mineral semanal, cujos teores são altos comparados aos da água residuária.

Entretanto, apesar de não apresentar diferenças estatísticas, as plantas do tratamento com água residuária tenderam $(0,05>\mathrm{P}<0,1)$ a apresentar maiores teores de $\mathrm{P}, \mathrm{Ca}, \mathrm{Mg}$ e B, provavelmente pelo "efeito de diluição" dos nutrientes ocorridos nas plantas do tratamento convencional, as quais cresceram mais. Este efeito pode ser notado pelo acúmulo de nutrientes, que foi maior nas folhas das plantas do tratamento convencional. O alto valor do acúmulo de $\mathrm{Mn}$ e $\mathrm{Fe}$ no tratamento convencional surpreendeu, pois não foram utilizados micronutrientes nesta adubação, a não ser o existente originalmente no substrato. Durante o desenvolvimento do ensaio, constatou-se que as plantas em ambos os tratamentos não apresentaram deficiência e nem toxidez de nutrientes aparente.

Os resultados referentes à análise nutricional foliar e à taxa de acúmulo de nutrientes nas folhas de copaíba (Quadro 6) mostram valores significativamente maiores nas plantas do tratamento convencional para os elementos $\mathrm{N}, \mathrm{K}, \mathrm{Mg}$ e S. Em função da adubação mineral semanal no tratamento convencional, os maiores teores de $\mathrm{Ne} \mathrm{K}$ já eram esperados, enquanto o alto valor de Mg surpreendeu por não ter sido utilizado este nutriente na adubação convencional. A superioridade no teor de S também é estranha, levando-se em conta a análise química do substrato (Quadro 2), pois foram obtidos maiores valores no substrato com água residuária.

A análise foliar no tratamento com água residuária da copaíba apresentou superioridade apenas para o B, pela existência deste elemento nessa água, pois ele está presente nos esgotos sanitários oriundos da utilização de sabão em pó e outros produtos de limpeza (Bastos, 1999). Quanto ao acúmulo dos nutrientes nos tecidos foliares

Quadro 5 - Análise química foliar (médias e desvio-padrão) e acúmulo de nutrientes nas folhas do Croton floribundus Table 5 - Chemical leaf status (means and standard deviation) and leaf accumulated nutrients for Croton floribundus seedlings

\begin{tabular}{|c|c|c|c|c|c|c|}
\hline & & \multicolumn{2}{|c|}{ Análise Química Foliar } & & \multicolumn{2}{|c|}{$\begin{array}{l}\text { Acúmulo de Nutrientes nas Folhas } \\
\text { (mg/muda) }\end{array}$} \\
\hline & & Á. Residuária & Convencional & & Á. Residuária & Convencional \\
\hline \multirow{6}{*}{ 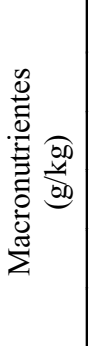 } & $\mathrm{N}$ & $18,25+/-1,26$ & $20,00+/-1,83$ & (n.s.) & 13,69 & 29,40 \\
\hline & $\mathrm{P}$ & $2,70+/-0,42$ & $2,08+/-0,39$ & (n.s.) & 2,03 & 3,05 \\
\hline & $\mathrm{K}$ & $16,25+/-1,50$ & $20,50+/-2,89$ & $(\mathrm{t}=2,613 \mathrm{p}=0,04)$ & 12,19 & 30,14 \\
\hline & $\mathrm{Ca}$ & $16,00+/-2,16$ & $13,25+/-1,26$ & (n.s.) & 12,00 & 19,48 \\
\hline & $\mathrm{Mg}$ & $3,98+/-0,71$ & $3,13+/-0,47$ & (n.s.) & 2,98 & 4,59 \\
\hline & S & $1,25+/-0,19$ & $1,18+/-0,09$ & (n.s.) & 0,94 & 1,73 \\
\hline \multirow{5}{*}{ 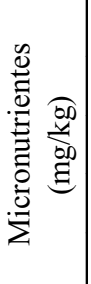 } & $\mathrm{B}$ & $60,75+/-9,29$ & $49,75+/-4,27$ & (n.s.) & 0,05 & 0,07 \\
\hline & $\mathrm{Cu}$ & $5,00+/-0,00$ & $5,00+/-0,00$ & (n.s.) & 0,00 & 0,01 \\
\hline & $\mathrm{Fe}$ & $218,25+/-30,28$ & $285,25+/-50,72$ & (n.s.) & 0,16 & 0,42 \\
\hline & $\mathrm{Mn}$ & $145,75+/-23,73$ & $194,00+/-12,03$ & $(\mathrm{t}=3,628 \mathrm{p}=0,0110)$ & 0,11 & 0,29 \\
\hline & $\mathrm{Zn}$ & $96,00+/-13,29$ & $88,75+/-8,02$ & (n.s.) & 0,07 & 0,13 \\
\hline
\end{tabular}

R. Árvore, Viçosa-MG, v.27, n.3, p.335-342, 2003 
Quadro 6 - Análises químicas foliares e taxa de acúmulo de nutrientes nas folhas da Copaifera langsdorffii (médias e desvio-padrão)

Table 6-Chemical leaf status and accumulated leaf nutrients for Copaifera langsdorffii

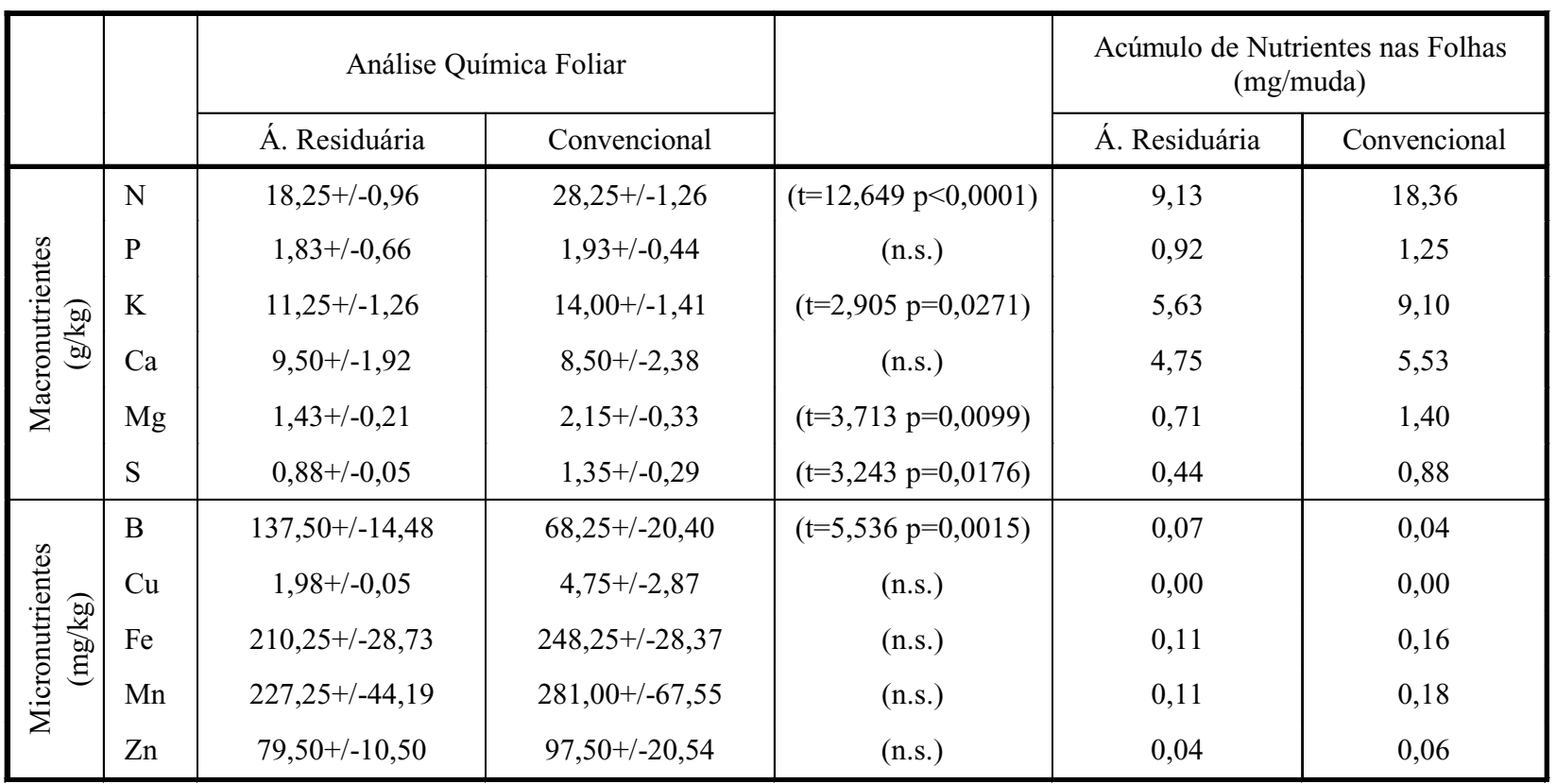

da copaíba, também foram obtidos maiores acúmulos no tratamento convencional, exceção feita ao boro. Também, para esta espécie, não foram observados sintomas de toxidez ou deficiência de nutrientes durante o experimento.

\section{CONCLUSÕES}

Os resultados mostraram que a água residuária pode ser utilizada na fertirrigação de viveiros para produção de mudas das espécies estudadas, pois todas as plantas se mostraram sadias, vigorosas, com bom desenvolvimento, boa sobrevivência, sem deficiência ou toxidez de nutrientes aparente. Além disto, o desenvolvimento do sistema radicular foi favorecido no sistema com água residuária, o que é uma característica desejável para maior sobrevivência das mudas no campo. Entretanto, constatou-se menor desenvolvimento geral das espécies, o que leva a crer que as mudas florestais produzidas com o uso da água residuária necessitarão de maior tempo no viveiro, quando comparadas às produzidas com fertilizantes minerais.

\section{AGRADECIMENTO}

Este estudo foi realizado com o apoio financeiro da FAPESP (processo 00/14827-4). Gostaríamos de agradecer aos funcionários da FCA: Claudinho, Dicão, S. João, Ieda, José Di Pieri, Zé Carlos e Rodrigo; e aos alunos da Pós-graduação: Magali R. Silva, Rodrigo de M. Trigueiro, Carlos C. Breda e Jeane A. Almeida, por toda colaboração no decorrer do experimento. Agradecemos também a três consultores anônimos da Revista Árvore, pelas sugestões e correções, que muito enriqueceram este trabalho.

\section{REFERÊNCIAS BIBLIOGRÁFICAS}

BASTOS, R. K. X. Fertirrigação com águas residuárias. In: FOLEGATTI, M. V. (Coord.) Fertirrigação: Citrus, flores e hortaliças. Guaiba: Agropecuária, 1999. 279 p.

COLE, D. W.; HENRY C. L.; NUTTER W. (Eds.) The forest alternative for treatment and utilization of municipal and industrial wastewater and sludge. Seattle: University of Washington Press, 1986.

R. Árvore, Viçosa-MG, v.27, n.3, p.335-342, 2003 
CROMER, R. N. Irrigation of radiata pine with wastewater: A review of the potential for tree growth and water renovation. Aust. For., v. 43, p. 87-100, 1980.

EMPRESA BRASILEIRA DE PESQUISA AGROPECUÁRIA - EMBRAPA. Centro Nacional de Pesquisa de Solos. Manual de método de análises de solo. 2.ed. Rio de Janeiro: 1997. 212 p. (EMBRAPA - CNPS. Documentos, 1).

FERNANDES, F. Estabilização e higienização de biossólido. In: BETTIOL, N.; CAMARGO, O. A. (Eds.) Impacto ambiental do uso agrícola do lodo de esgoto. Jaguariuna: EMBRAPA MEIO AMBIENTE, 2000. p. 45-67.

GASI, T. M. T. Opções para tratamento de esgotos de pequenas comunidades. São Paulo: CETESB, 1988. 36 p. (Série Manuais, 3).

GONÇALVES, J. L. M. et al. Aplicabilidade de biossólido em plantações florestais: II. Efeito na fertilidade do solo, nutrição e crescimento das árvores. In: BETTIOL, N.; CAMARGO, O. A. (Eds.) Impacto ambiental do uso agrícola do lodo de esgoto. Jaguariúna: EMBRAPA MEIO AMBIENTE, 2000a. p. 179-195.

GONÇALVES, J. L. M. et al. Produção de mudas de espécies nativas: substrato, nutrição, sombreamento e fertilização. In: GONÇALVES, J. L. M.; BENEDETTI, V. (Eds.) Nutrição e fertilização florestal. Piracicaba: IPEF, 2000b. p. $80-102$.

GUIMARÃES, A. B. et al. Treatment of domestic wastewaters in rural zone by using aquatic plant system. In: INTERNATIONAL SYMPOSIUM ON SANITARY AND ENVIRONMENTAL ENGINEERING, 2000, Trento. Proceedings... Trento: Hyper, 2000. p. 237-243.
HARRISON, R. B. et al. Recycling of industrial wastes and forest harvesting residues on forest lands. In: SIMPÓSIO BRASILEIRO DE PESQUISA FLORESTAL, 1., 1993, Belo Horizonte. Anais... Belo Horizonte: Sociedade de Investigações Florestais, 1993. p. 255-264.

HENRY, C. L.; COLE, D. W., HARRISON, R. B. Use of municipal sludge to restore and improve site productivity in forest: The pack forest sludge research program. Forest Ecology and Manegement, v. 66, p. 137-149, 1994.

\section{LABORATÓRIO NACIONAL DE REFERENCIA} VEGETAL - LNRV. Análise de corretivos, fertilizantes e inoculantes. Métodos oficiais. Brasília: Secretaria Nacional de Defesa Agropecuária. Ministério da Agricultura, 1988.

MALAVOLTA, E.; VITTI, G. C.; OLIVEIRA, S. A. Avaliação de estado nutricional das plantas : princípios e aplicações. 2.ed. Piracicaba : Associação Brasileira para a Pesquisa da Potassa e do Fosfato. 1997. 319 p.

MORAIS, S. M. J. et al. Uso do lodo de esgoto da Corsan Santa Maria (RS), comparado com outros substratos orgânicos. Sanare, v. 6, p. 44-49, 1997.

POGGIANI, F.; GUEDES, M. C.; BERNADETTI, V. Aplicação de biossólido em plantações florestais: I. Reflexo no ciclo dos nutrientes. In: BETTIOL, N.; CAMARGO, O. A. (Eds.). Impacto ambiental do uso agrícola do lodo de esgoto. Jaguariuna: EMBRAPA MEIO AMBIENTE, 2000. p. $163-178$.

POSTEL, S. L.; DAILY, G. C.; EHRLICH, P. R. Human appropriation of renewable fresh water. Science, v. 271, p. 785-788, 1996. 